\title{
José de la Cuadra
}

Parcialmente a causa de los desastres económicos en el Ecuador entre los años de 1918 y 1925 y deseando mejorar la situación de su triste país, un grupo de autores trató, como dice Luis Alberto Sánchez, de "crear literariamente en el ambien. te feudal de la sierra ecuatoriana las mismas realidades que en los medios industriales de Europa". " Se podía notar en la literatura de este grupo la influencia de Manuel González Prada. José Eustasio Rivera, Alcides Arguedas, José Vasconcelos y, sobre todo, de José Carlos Mariátegui. También era evidente la de Henri Barbusse y otros muchos autores europeos.

En las novelas de este grupo casi siempre se halla una ideología política de izquierda y casi todos sus miembros incluyen en ellas aberraciones sexuales, multiplicando y acumulando los detalles naturalistas. Trataron, en muchos casos, de combinar lo que llamaron el Freudianismo y el Marxismo. Su tendencia hacia los extremos se hizo más evidente a causa de la oposición vehemente que los elementos conservadores del Ecuador les hicieron. Además del naturalismo, hicieron hincapié en un regionalismo y un simbolismo algo exagerado.

Hubo muchos novelistas en este grupo de la sierra y de la costa: Pedro Jorge Vera, Jorge Icaza, Adalberto Ortiz, Deme trio Aguilera Malta, Enrique Gil Gilbert y otros. Pero el au. tor que adelantó más la nueva forma fue José de la Cuadra.

José de la Cuadra nació en 1904 y murió en 1941. Estudió en el Colegio Vicente Rocafuerte y, más tarde, llegó a ser profesor de literatura allí mismo. Asistió a la Universidad de

1 Sảnchez, Luis Alberto, América, novela sin novelistas, Santiago, 1940, p. 30. 
Guayaquil y tomó parte en su política, llegando a ser presidente de la Federación del Sur de Estudiantes Ecuatorianos y representante del Ecuador en la Federación de Estudiantes Hispano Americanos. Fue cónsul en varios países, entre ellos el Uruguay y la Argentina. En el Ecuador llegó a tener varios puestos en el gobierno. Era abogado, aunque en esta profesión nunca tuvo mucho éxito.

Desde 1924 colaboró en dos revistas del grupo, América y Savia, y en ellas pueden hallarse algunos de sus primeros cuentos. En 1925 publicó dos obras de las cuales más tarde se avergonzó, Olga Catalina y Perlita Lila. Continuó escribiendo cuentos, ganando de vez en cuando premios, como por ejemplo, con Sueño de una noche de Navidad en 1929, bajo el pseudónimo de Orduno Zarnudio. En 1930 publicó su primera colección de cuentos, Amor que dormía, e incluyó en este volumen los primeros cuentos que escribió: Madrecita falsa (1923), Amor que dormía (1926), Incomprensión (1926) y otros. Se muestra en estos cuentos creador de caracteres e intérprete de la lucha interior.

Algunos de ellos son parecidos a los de Ilya Ehrenburg en la combinación de ironía con situaciones eróticas. Para Cuadra, la emancipación sexual era parte del rechazo de los valores antiguos de la burguesía.

En las obras que publicó después Cuadra continuó formando sus tramas basándose en las interpretaciones contemporáneas de la psicología anormal, pero trató más deliberadamente de hallar alguna correspondencia entre las ideas que estaba comunicando y la manera de su presentación. Así, se apoyó más en detalles naturalistas $\mathrm{y}$, puesto que su práctica había sido en el Derecho, dio énfasis a los crímenes sexuales. Su conocimiento de los criminales le ayudó a retratar violencias de varios tipos; mostró su interés intenso en tipos anormales y analizó su psicología con una gran sutileza. Además, continuó insistiendo en los derechos de los pobres contra los que él consideró opresores.

En Repisas, 1931, obra dispuesta en cuatro divisiones, usa una variedad de técnicas. Algunos de sus cuentos se basan en un solo incidente de poca duración; otros duran semanas o aun años; algunos dependen de la pintura de caracteres, y otros, de 
la descripción del fondo. Casi todo el libro está lleno de seducciones y contiene también una esperanza en la revolución social del futuro, por ejemplo, "Sí, pegue usted, señor empleado, en las espaldas del pueblo sufrido y aguantón; rocín suyo es ahora, pero más adelante usted caerá, caerá no, se levantará y será pueblo."'

Cuadra dice que quiere quebrar con la manera tradicional de tratar los mitos, y lo hace con violencia a causa del conservatismo abyecto del Ecuador. Construye una situación donde la miseria sigue a la miseria para darnos una representación gráfica de los horrores de situaciones de la vida actual. De todos sus cuentos, quizás, Venganza y Chumbote son los más típicos. Nos muestra las circunstancias degradantes de la vida de los ecuatorianos. El primer cuento trata de un indio que mata a su mujer encinta y después mata al tabernero que le había vendido aguardiente malo. Así, obtiene un tipo de venganza contra la sociedad que le había vuelto bruto. Chumbote, considerado tonto por su patrón, es maltratado por la patrona. la cual sospecha que Chumbote es el hijo ilegítimo de su esposo. Cuando ella muere, Chumbote obtiene una gratificación pervertida al lado de su cadáver, obteniendo la venganza social por medio del insulto. La violencia de este cuento, como ejemplo de un pervertido freudianismo es típica; sus obras están llenas de pesadillas sexuales que en realidad son símbolos sociales. De alguna manera Cuadra junta esto con lo que él llamaría la violación y corrupción del Ecuador. La combinación de sexo, esclavitud y tortura no cabe fácilmente dentro de los límites de un solo cuento. Otros cuentos del libro tratan de las aventuras de un alcohólico acusado falsamente de un robo (Miedo), de un cura que mata a un muchacho indio ( $E l S a$ cristrán), y de los amores de los montuvios y las promesas fal. sas de un gobierno corrompido ( $E l$ desertor). El sentimiento del autor es muy parecido al discurso de Luis Cervantes en Los de abajo sobre este tema: "Un jefe de partido les prometía encantados paraísos; los enganchaba en sus filas, aprovechábase del tesoro de sus arrestos y su sangre; triunfaba; y luego, ellos, los vencedores de veras, a curar sus heridas, explotar la 
caridad extranjera con la exhibición de sus lástimas físicas."3 Horno (1932) es simbólico del cruzamiento de indios y españoles. Es una colección de aventuras, de pasiones elementales, llenas de violencia, homicidio, crueldad y venganza, pero, a la vez, busca la reivindicación de los desgraciados del Ecuador. A pesar de esto, se halla cierta sobriedad de estilo, del cual ha dicho Torres-Rioseco: "En los cuentos montuvios de Horno se ha metido más adentro en la conciencia filosófica y humana del indio y ha adquirido cierto reposo, cierta condición de equilibrio de que carecía antes."

La solución de Cuadra aquí es semejante a la de los otros autores de su grupo. El nos ofrece la hermandad de los hombres y la creación de una sociedad sin clases. El ambiente político, social y económico formó a Cuadra de manera que da expresión no sólo a lo que ya existe sino también a lo que quiere efectuar. Es', sin duda, un reformador, y en sus temas destaca un simbolismo por medio del cual espera el autor evocar compasión en sus lectores. Ha examinado centenares de historias criminales y ha proyectado éstas sobre la página esperando que el lector halle en ella lo significativo. Parte de la calidad característica de Cuadra yace en su ferocidad. Los cuentos de in. cesto, pobreza, masturbación o muerte, por horribles que sean, exhiben una vitalidad que nace de la misma groseria, calidad de grotesco y brutalidad.

Los cuentos de Horno revelan de nuevo una variedad de técnicas. En algunos hay movimiento rápido, con pocos episodios que complican la presentación del tema principal. En la mayor parte, sin embargo, hay una variedad de episodios para reforzar sus opiniones de la lucha contra la injusticia ecuatoriana. Dentro de este plan hay cuentos con un desarrollo gradual con un solo clímax; otros tienen una serie; algunos revelan la acción por los discursos de los caracteres; otros dependen de los comentarios del autor, y otros usan una mezcla de narración directa y conversación.

Uno de los cuentos más largos del volumen, Barraquera. tienen como protagonista a una vieja que sueña con su juven.

3 Ibid., p. 117.

4 Torres Rioseco, A., "La novela de tema indígena en el Ecuador", Publications in Modern Pbilology, 1939, p. 234. 
tud y que lucha para resolver los problemas de la vida. Cuadra retarda el movimiento, incluye muchos episodios y nos muestra por estos episodios varios aspectos de la escena ecuatoriana. Describe solamente un carácter, pero por medio de sus recolecciones sabemos la vida de otros. El lenguaje de la mujer y sus comentarios dan a Cuadra la ventaja de poder definir el carácter básico de la mujer sin acudir al análisis hondo. Muestra la condición terrible de las minas, por ejemplo, en la muerte de un niño cuya madre debe dar su leche al hijo del hacendado. Barraquera tiene bastante regionalismo: una fiesta bautismal, escenas del mercado, las chicherías, y siempre las lágrimas del pueblo que se queja de que aun los santos protejan sólo a los ricos. La niña de Concha muere de hambre, y Cuadra insinúa que es mejor así porque la suerte de la mayor parte de las pobres del Ecuador es, como dice el autor ser: "mujeres-y pobres, es decir, carne propicia de los prostíbulos baratos."

En Colimes Jotel, Cuadra es el observador, y el efecto del cuento depende de la presentación del fondo. No hay trama, y el cuento es más o menos un bosquejo de la vida estática, y su calidad importante está en la descripción del ambiente. Colimes es el hotel a donde van los montuvios que vienen a la ciudad para ser robados e infectados. En Chichería tampoco hay un gran movimiento trágico, pero se nota de nuevo la violencia, horror, y violación en su descripción de la tragedia de una gente que vive en desarmonía con sus deseos. La chichería se abre a las seis, se encienden las luces y vienen los clientes de los barrios pobres de la ciudad. Aquí se oye una guitarra, allí las inevitables discusiones y muchas veces las luchas que terminan con la muerte de uno de los combatientes. La patrona muere como resultado del uso excesivo de afrodisiacos, y vemos otra vez que en Cuadra la necesidad física nivela a todos los hombres y a todas las clases. Temas semejantes se ven en los otros cuentos del libro.

En el cuento más largo, Banda del pueblo, nos da descripciones directas de varios caracteres, pasando rápidamente de uno a otro y de incidente a incidente para observar los fenómenos sociales de su país. La banda consiste en ocho hombres

5 Cuadra, José de la, Hơno, Guayaquil, Filantrópico, 1932, p. 38. 
y un muchacho. Viaja por todo el país, visita todos los pueblos donde hay fiestas, y Cuadra se aprovecha de esto para describir los bailes, fiestas religiosas y funerales. Aquí hallamos todas las maldades sociales dei Ecuador, la injusticia, el engaño, el fraude, los blancos malos, la política sucia y los abogados no honrados. La tragedia de los hermanos Alancay es un asunto de todos los días: "Los Alancay, sin saber cómo, se encon" traron con que, tras un año de labor ruda y continuada, no guardaban nada ahorrado, apenas habían comido, estaban casi desnudos, y para remate tenían con el patrón una cuenta de cien sucres cada uno." 6

$\mathrm{El}$ problema indio está bien descrito en los dos cuentos fi nales, Ayoras falsos y Merienda de perro. Ayoras, monedas falsas, son dadas a un indio que vende como esclavo a su hijo. La esclavitud es realizada cuando el indio no sólo pierde sus derechos sino que es castigado por haberse atrevido a quejarse de la acción del blanco. Como dice Cuadra, el gobierno protege siempre al gamonal que hace "tanto" por la producción deı país. Al final, el indio lanza una piedra al muro de la hacienda. lo que es más que una acción de enojo personal: es símbolo de la resistencia pasiva de la clase sumergida.

....En Merienda de perro, pierde un indio la oveja de su patrón y sabe que será castigado duro porque en su sociedad feudal la oveja vale más que él. Busca y halla a la oveja antes de ser descubierto; se maravilla del silencio del perro de guarda, $y$, mientras da gracias a Dios, halla al perro mordiendo el cuerpo parcialmente devorado a su hijito. Cuadra construye con cuidado este cuento para obtener un solo efecto y no hay palabra que no adelante su plan de crear esta sola impresión. La ac. ción se dirige hacia la crisis rápidamente, se intensifica el interés por el uso del "suspense" $y$, finalmente, de súbito, el punto culminante final del cuento es presentado. Aunque Cuadra muestra muchos aspectos de la miseria de la vida del indio a través de los pensamientos de la esposa que tiene que dejar a su hijo para ir a dormir con el patrón, evita poner demasiado énfasis en el sentimiento de la situación y nos da simplemente unos detalles que logran este efecto sin esfuerzo.

- Ibid., p. 148. 
En 1934, Cuadra escribió su única novela completa, Los Sangurimas. Llamarla novela no es ser exacto, porque es más bien una serie de capítulos unificados flojamente por los caracteres principales. Aunque la novela es desigual en su estructura, muchos de los capítulos son inolvidables. Unos pocos detalles llenan las necesidades narrativas; cada capítulo está subdividido en una serie de cortas secciones con título, de media página cada una. Cada sección constituye un concentrado y necesario aspecto del tema. Las tres principales, simbólicas del viejo Sangurima y sus descendientes, son "El tronco añoso", "Las ramas robustas" y "Torbellino en las hojas". Esta técnica de dividir una novela en lo que pudieran ser varios cuentos cortos conectados por un tema central ocurre con pocas variaciones en las obras de casi todos los novelistas del Ecuador, por lo menos hasta el año de 1950. Mariano Latorre explica uno de los motivos de esto: "En la técnica del cuento los actuales escritores del Ecuador son artistas acabados. Les tocó nacer, sin duda, cuando la novela corta no tenía ya secretos en la historia literaria. No son precursores sino temperamentos de selección que descubren en forma admirable el espectáculo bochornoso del nativo en su tierra." ?

Los Sangurimas nos presenta una galería de estudios patológicos, apetitos pervertidos, locura y degeneración sexual que parece casi natural en el fondo primitivo que le da el autor. Cuadra insiste siempre en que los impulsos reprimidos se expresan finalmente en aberraciones y anormalidades. La trama relata brevemente cómo Nicasio Sangurima, patriarca de la tribu, hereda un terreno sobre el cual se desarrolla un pleito. Nicasio tiene tres hijos legítimos, Francisco, Eufrasio y Ventura. Las hijas de Ventura vienen a visitarle y los hijos de Eufrasio tratan de violarlas. Ventura lo prohibe y los hijos matan a una de las hijas. Terencio, hijo ilegítimo de Nicasio, les denuncia a la policía. Nicasio esconde a sus nietos y, después de una batalla con la policía, se vuelve loco. Los caracteres no son representantes del hombre-masa, y no se trata simplemente de tipos como el indio, el cholo, o los de "arriba", contra los de "abajo". Terencio, por ejemplo, es un cura del pueblo que no

7 Latorre, Mariano, Atenea, 1935, XXXII, p. 135. 
es el cura típico que se halla en la novela contemporánea. Aunque es un borracho, no exhibe la falta de corazón de la mayor parte de los curas de la novela ecuatoriana. No es villano completo, y el montuvio no es víctima "buena". Sabe explicar la religión de una manera curiosa. Comprende que el montuvio es un hombre de pasiones desatadas e implacables con sus enemigos. "Si yo les digo a los montuvios que cuando Malco le dio una bofetada en la mejilla a Jesucristo éste volvió la otra, se escandalizarían y pensarían que Jesucristo era un cobardón que no vale la pena tomarle en cuenta... Yo les digo más o menos... Saben lo que hizo el santo varón. En vez de haberle rajado el alma que era lo que provocaba, como él era de tan buen corazón, apenas se contentó con decirle.... Anda a golpear a tu madre". ${ }^{8}$ Cuadra exhibe aquí un tipo de ingenio y cualidades picarescas que usa con buen efecto en sus descripciones de lo feo y triste.

Se ve en esta novela el simbolismo tan evidente en la novela ecuatoriana. El símbolo telúrico de Nicasio es el matapalo que hunde sus raíces en el suelo ecuatoriano. Nicasio, como su símbolo, es el árbol que se eleva sobre la otra vegetación y los otros Sangurima son las ramas. A pesar de los caracteres anormales se puede ver la comprensión, y aun amor, que tiene por el montuvio.

Pero no se puede evitar los problemas sociales. El blanco seduce a la campesina. Las cárceles se emplean solamente para los pobres. Los jueces son corrompidos. No se puede decir que una página específica exhibe sutileza o talento, pero el efecto total de lo brutal y lo sensual es bastante imponente, $y$ aun las ocurrencias rutinarias de la obra contribuyen a la impresión duradera como cualquiera de los clímax de horror. Sin embargo, no todo es horror. Hay pasajes tranquilos que alternan con escenas de violencia extravagante. Casi siempre sus episodios tienen éxito porque exhibe un dominio crítico sobre sí mismo y sabe poner las escenas violentas en relieve. Sabe cuándo debe participar y cuándo debe retirarse como espectador irónico.

Hay en la obra simplicidad y profundidad, vulgaridad,

8 Cuadra, José de la, Los Sangurimas, Madrid, Cenit, 1934, pp. 55-56. 
tragedia y un sentido de lo cómico. Antonio Montalvo la consideró: "Novela acabada, por su perfección de síntesis, en donde se logra la más feliz superación estética. Accionantes en los limites de su medio físico, vivos en su preponderancia indiviciual, inconfundibles y humanos, cumpliendo las normas sociales específicas, de su psicología, su fisiología, sus intentos, su amoralidad, su superstición, que es casi su mitología misma, su naturaleza bravia... tipos montuvios reales."9

Completan el volumen los cinco cuentos cortos descritos a continuación Sangre expiatoria trata de varias supersticiones sobre la virginidad y el cielo y termina en la seducción y la muerte. $E l$ candado se preocupa de la violación de una mendiga imbécil y su muerte; Barraganía, nos muestra el incesto sobre el cual Cuadra parece tener una preocupación obsesiva; Shishi la chiva habla de la miseria, hambre y esclavitud de la gente de la sierra, y Calor de yunca pinta de nuevo el tema predilecto de Cuadra, el incesto. Trata de capturar el tormento tropical de la juventud que busca la madurez y lo usa como parte de su rebelión.

En 1935, en dos capítulos de su novela, nunca publicada, Palo e Balso, habla de la violación y del honor montuvio, combinados con la venganza simbólica contra la sociedad. El patrón, cuya hija es secuestrada por Máximo, el cuatrero, le manda ganado marcado con hierro. Máximo le devuelve la hija encinta y también marcada. Cuadra nos muestra un humorismo que tiene a veces matices conmovedores en la descripción de algunos de sus caracteres montuvios y en su diálogo.

En Guasintón (1938), su última colección de cuentos, Cuadra muestra claramente la influencia de Horacio Quiroga, sobre todo de los cuentos Los mensú y Anaconda. El cuento de Guasintón trata de un caimán que vive en un río respetado y temido de todos hasta que comete el error de comerse al perro predilecto de un gamonal; éste ofrece un premio grande para el que lo cace. En una cacería matan al caimán, pero hay que usar trece expertos cazadores para hacerlo. El huésped, P'al caso y Partición tratan del honor entre los montuvios, y Cubillo y Ruedas tienen interés como estudios de la

9 Montalvo, Antonio, América, 1934, IX, p. 122. 
psicología de los montuvios. Selva en llamas describe un asesinato causado por la destrucción de un ideal de pureza sexual de una mujer amada y muestra una influencia notable de Máximo Gorki. La solterona y La tigra tratan temas de virginidad y superstición, mientras que Disciplina nos interesa porque se anticipa a $A_{\Delta}$ dalberto Ortiz en describir a los negros de Esmeraldas y al efecto de la indoctrinación militar en los campesinos primitivos. Los dos cuentos más típicos de su preocupación social son Santo Nuevo y Se ha perdido una niña. El primero merece especial mención, no tanto por el tema ordinario de un rico blanco que trata de seducir a la hija de un trabajador, sino que más bien porque presenta la reacción primitiva y la ideología del campesino conservador, el cual atribuye la preservación de su honor al milagro del nuevo santo, San Lenín, de quien tanto había oído hablar. Cuadra sugiere que la miseria de los trabajadores continuará hasta que se halle la cura en el socialismo. "Era hijo de peones conciertos y descendía de un linaje de esclavos que consumieron sus existencias miserables, siempre al servicio de los mismos patrones, en el antiguo latifundio... La revolución social... Lenín es el santo máximo de la nueva religión. . . la dictadura del proletariado." 10

El segundo cuento, además de pintar el trabajo y las luchas del montuvio, discute también la posición de los huérfanos sin leyes para su protección. Las mujeres tienen un solo fin trágico: "Primero un hombre; luego muchos hombres, todos los hombres. Después del prostíbulo, el hospital y más tarde la morgue y la tumbra." "11 El tema de la corrupción legal recibe atención, por ejemplo, en el caso del rico gamonal que paga a la policía para matar a un "enemigo público... Ley de fuga, pues, enen ígo público. Enemigo de terrateniente sería."12 En la segunda mitad de Guasintón el autor relata lo que llama "crónicas" de varios ecuatorianos y europeos.

Los monos enloquecidos fue empezado en 1931, pero el manuscrito se perdió durante 17 años. La madre de Joa-

10 Cuadra, José de la, Guasintón, Quito, Educación, 1938, pp. 86-91.

11 lbid., p. 66.

12 Ibid., p. 33. 
quín Gallegos Lara lo halló un año después de su muerte entre las posesiones de su hijo y fue publicado incompleto en 1951 por la Casa de la Cultura Ecuatoriana. La trama no es de mucha importancia; y pinta los viajes del héroe por los océanos del mundo, sus bodas y su experiencia en el litoral ecuatoriano como dueño de una hacienda. El protagonista, Gustavo Hernández, una de las mejores creaciones de Cuadra, es algo loco y le dejamos al final del libro buscando tesoros y tratan. do de realizar su sueño de cambiar a los monos en hombres que le sirvan. Vivimos con Gustavo las sensaciones de un viajero mundial que se siente hombre primitivo, vuelto milagrosamente a su ambiente natural después de haber sido expuesto a toda clase de influencias extranjeras. Nos presenta la inevitable discusión de las condiciones sociales; el terrateniente, dueño de vidas y haciendas, es una figura de la Edad Media. Esta obra, sin embargo, llena de un humorismo picaresco, sobre todo en las discusiones de los descendientes de la aristocracia española en Guayaquil, no intenta probar nada. Pero Cuadra menciona lo que considera la causa principal de las didicultades ecuatorianas. "El león ibero no consiguió desflorar irremediablemente a la doncella América. De esta falta de compenetración íntima, pluscuamperfecta, el divorcio que luego se planteó como consecuencia; de ahí que el conquistador no fue un colonizador eficaz y que el único lazo que se estrechó entre los hispanos y los indios fuera el odioso de dominadores y dominados, de señores y vasallos". ${ }^{13}$ Aunque hay escenas de horror y bastantes páginas grotescas, no hay tantos crímenes brutales como en sus cuentos cortos. El autor también nos presenta un retrato excelente de las supersticiones del Ecuador. Masa Blanca, el viejo brujo, usa hechizos y encantamientos, cura a los enfermos y halla un tesoro escondido. Los peones creen en buenos y malos espíritus y en pactos con el diablo.

Cuadra ha escrito dos ensayos largos, Doce siluetas, (1934), y El montuvio ecuatoriano, (1937), que merecen atención. E] primero consiste en doce ensayos; muchos de ellos analizan los otros autores del mismo grupo. Para Cuadra, Aguilera IMal-

13 Cuadra, Jsé de la, Los monos enloquecidos, Quito, Casa de la Cultura, 1951, p. 13. 
ta tiene conciencia social, Gil Gilbert es un escritor independiente con lo que había llamado Barbusse "realidad de fondo", y así analiza a otros, como Gallegos Lara y Pareja Diez Canseco.

El montuvio ecuatoriano contiene casi todos los elemenros sociales que se hallan en sus cuentos. Uno de los motivos del libro, dice Cuadra, es contribuir al desarrollo de la novela contemporánea por medio de un estudio serio de la cruda materia, de la cual los novelistas ecuatorianos obtenían sus temas, y combatir a esos escritores que escondían su ignorancia de los montuvios bajo aspectos superficiales como la gramática iletrada y la mención de unas pocas supersticiones. Discute los problemas de la zona montuvia, los inadecuados métodos de cultivo y la injusticia de los blancos, Analiza las costumbres y nos muestra cómo cada familia en una entidad separada, aislada, o casi aislada, por medio del sistema patriarcal de las regiones rurales. Hay varios estratos sociales entre los montuvios: el pobre campesino que pide prestado el dinero para sembră y después debe vender la cosecha al rico terrateniente por lo que quiera pagar éste; el peón, engañado a cada paso, compra en la tienda del patrón y es explotado por el cura y el teniente político. Para él, dice Cuadra, la única esperanza es una revolución que distribuya más adecuadamente la tierra.

José de la Cuadra tiene cualidades que no comparte con los otros escritores ecuatorianos. Sus obras poseen un humorismo sardónico como parté de su textura y, aunque en muchas de sus obras sus descripciones de la vida y tragedia de su pueblo no se quedan atrás de las escenas brutales escritas por sus contemporáneos, le falta mucho de la amargura de Humberto Salvador. Tampoco nos da un cuadro tan sin esperanza y sin solución como Icaza. El uso de la ironía, en vez de la denunciación, no amengua el impacto social de su obra. Sus cuentos' están llenos de sexo, de perversión y también de un simbolismo provocativo. Le interesaron asesinatos y anormalidades sexuales, porque le fascinó la brutalidad de la vida. A pesar de lo mórbido y lo repelente en sus descripciones de fenómenos psico-sexuales, sus producciones tienen valor psicológico como estudios de la fuerza del sexo de una sociedad atrasada. Al deplorar sus generalizaciones y su interés en la degradación se- 
xual, no se debiera olvidar el valor de su contribución a la novela ecuatoriana, al ayudarla a liberarse de límites estrechos. Se atrevió a rebelarse para tratar, como él quería, todas las' for. mas de experiencia. La mayor parte de sus montuvios sufre-de la pobreza y de la degradación moral, y a veces sus creacio. nes parecen melodramáticas, pero tienen autenticidad, sobre todo en Los Sangurimas y en Los monos enloquecidos.

En la mayor parte de sus cuentos las circunstancias abru. man a la víctima y los acontecimientos irresistiblemente im. pulsan al hombre a un destino trágico. Casi toda la vida que presenta es trágica, y cuando el héroe sale victorioso, usualmente su victoria es simbólica. Cuadra creyó siempre que la agitación política de su juventud fracasó porque buscó un cambio de gobierno en vez de un entendimiento de la vida humana. Asi es que en su obra da importancia a los' valores humanos, exhibiendo la compasión de un psicólogo que ha penetrado el alma montuvia. Y así podemos terminar citando el juicio de Benjamín Carrión: "Es que fue ante todo, sincero. $\mathrm{Y}$ siendo audaz, muy respetuoso ante la obra de arte. No utilizó la crudeza expresiva como un cohete restallante para deslumbrar o atemorizar incautos, sino como necesidad artística. No gritó audacias ideológicas, no hizo docencia expresa, pero cuánto enseñó y enseñará aún, para la justicia y el arte, este maestro permanente."14

KesSel Schwartz University of Vermont

14 Carrión, Benjamín, El nuevo relato ecuatoriano, Casa de la Cultura, Quito, 1950, p. 168. 
